\title{
Multi-axial fatigue numerical crack propagations in cruciform specimens
}

\author{
Venanzio Giannella, Michele Perrella \\ Dept. of Industrial Engineering, University of Salerno, via Giovanni Paolo II, Fisciano (S A), Italy \\ vgiannella@unisa.it, bttp://orcid.org/0000-0002-4410-9484 \\ mperrella@unisa.it, bttp://orcid.org/0000-0002-3617-2328
}

ABSTRACT. Two cracks, initiated from the opposite tips of a central notch inclined by $45^{\circ}$, were considered in cruciform specimens made of Ti6246. A static load was applied to a cruciform arm while a cyclic load was applied along the other arm.

Fatigue propagation of cracked specimens was performed by means of Dual Boundary Element Method (DBEM) and Finite Element Method (FEM) codes. For crack path assessment, the Minimum Strain Energy Density (MSED) and the Maximum Tensile Stress (MTS) criteria were adopted in DBEM and FEM approaches, respectively. Moreover, the J and M integrals' formulations were used to evaluate the SIFs along the crack fronts for DBEM and FEM codes, respectively. Crack-growth rates were predicted by using a Walker law, calibrated on mode I fracture experimental data.

A good agreement between numerical and experimental crack paths was obtained.

KEYWORDS. Cruciform specimen; HCF; Multiple cracks; DBEM; Crack path.

\section{OPEN ACCESS}

Citation: Giannella, V., Perrella, M., Multiaxial fatigue numerical crack propagation in cruciform specimens, Frattura ed Integrità Strutturale, 48 (2019) 639-647.

Received: 30.11 .2018

Accepted: 31.01 .2019

Published: 01.04.2019

Copyright: (C) 2019 This is an open access article under the terms of the CC-BY 4.0, which permits unrestricted use, distribution, and reproduction in any medium, provided the original author and source are credited.

\section{INTRODUCTION}

$\mathrm{O}$ ver the past few decades, many efforts have been made in the modeling and simulation of three-dimensional crack propagation problems. Early works dealt with appropriate representation of intricate cracks, and calculation of Stress Intensity Factors (SIFs) along the crack fronts [1]. As crack propagation capabilities have been developed, many researchers proposed frameworks necessary to model the extending crack with minimal user workload, for instance by FEM codes, such as FRANC3D [2], CRACKTRACER3D [3], ZENCRACK [4], and by DBEM codes, such as BEASY [5]. These approaches currently are used for automatic 3D fatigue crack-growth simulations in large structures $[6,7]$, in presence of residual stresses due to plasticity [8-12] and considering load spectrum effects [13]. Furthermore, hybrid FEM - DBEM submodelling procedures have been presented along the years [14-16]: these approaches couples the FEM versatility, for global problem modelling, and the higher efficiency of DBEM for crack-growth simulation in small subdomains.

In the past, non-planar 3D crack-growth algorithms typically adopted 2D mode I/II crack-growth theories, well suited for many engineering applications. However, as the capability to model nonplanar cracks in complex geometries has been developed, the demand for a more detailed crack path prediction has led to use more complex propagation criteria that 
include low-cycle fatigue/high-cycle fatigue (HCF/LCF) interactions, Mixed Non-Proportional Loading (MNPL), fracture mode asymmetry and both elastic and fracture resistance anisotropy.

Legacy crack-growth criteria, such as the Maximum Tangential Stress criterion [17], consider proportional loading $\left(\mathrm{K}_{\mathrm{II}} / \mathrm{K}_{\mathrm{I}}\right.$ $=$ constant throughout one cycle), and define the crack-growth along a $K_{I I} \approx 0$ path. When the loading condition is not proportional, the relative ratios of $\mathrm{K}_{\mathrm{I}}, \mathrm{K}_{\mathrm{II}}$, and $\mathrm{K}_{\mathrm{III}}$ vary over time during the cycle, making the setup of effective crack path criteria more difficult. MNPL condition occurs when static and cyclic loads simultaneously act along different directions, as for example in a turbine blade where the steady state centrifugal load couples with the vibrations of the blades (Fig. 1).

The blisks, i.e. turbomachine components that integrate rotor disk and blades in a single piece, are of common use in aero engines for all compressor stages due to the significant weight savings compared to traditional configurations with blades mounted in disk slots. The latter design could be affected by catastrophic failures if a crack in the blade slots, propagating because of HCF-loading, turned into the disk due to centrifugal LCF-loading condition. Thus, $45^{\circ}$ centrally notched cruciform specimens made of Ti6246 plate, were proposed as a potential simplification to analyze this phenomenon [18]. A static load was considered for simulating the LCF loading whilst a cyclic load, applied perpendicularly to the static load at a frequency of $5 \mathrm{~Hz}$, for the HCF loading condition. Several experimental tests were performed for different ratios between static and cyclic loads and the resulting crack paths and crack propagation rates were analyzed and compared with numerical results.

This work can be seen as an extension of [18] which presented the experimental outcomes here reported and the related numerical results performed with the FEM code CRACKTRACER3D. Here we present our numerical results performed with the FEM code FRANC3D and the DBEM code BEASY.

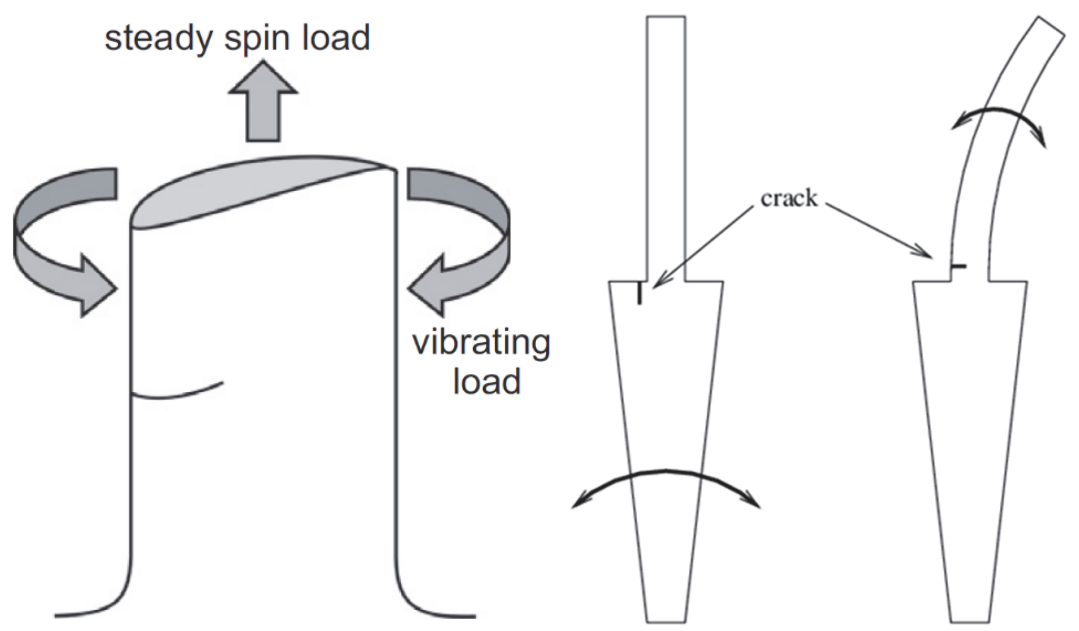

Figure 1: Complex loading conditions on a cracked turbine assembly of rotor disk and blade.

\section{EXPERIMENTAL TESTS}

E xperimental tests contained in this work have been taken from literature [18] and are here reported for more clarity. Different ratios of HCF and LCF loading conditions were considered for the experimental tests, providing corresponding crack propagation directions. A list of the tests considered in this work is summarized in Tab. 1. Main mechanical and fracture properties of the specimens' material are listed in Tab. 2.

In a first experimental test (Test I), a static load equal to $24 \mathrm{kN}$ was considered together with a second perpendicular load cycling between $-8 \mathrm{kN}$ and $+8 \mathrm{kN}$. A second test (Test II) was carried out with a different stepwise increment of the static load from $3 \mathrm{kN}$ to $12 \mathrm{kN}, 18 \mathrm{kN}$ and finally to $12 \mathrm{kN}$, keeping the cyclic load amplitude at the fixed value of $24 \mathrm{kN}$ with $\mathrm{R}=-1$. Only the first two load steps were considered in this work since cracks bifurcated during load case three [18].

A pre-cracking procedure was realized in order to produce two initial cracks from the two notch tips. To this aim, an equal cyclic load $(\mathrm{R}=0.1, \mathrm{f}=5 \mathrm{~Hz})$ was applied to both axes and, starting from an initial magnitude of $8 \mathrm{kN}$, the cyclic load was increased stepwise, based on the fact whether a crack was initiated or not. After successfully producing cracks from the notch tips, the load was stepwise reduced to its initial value in order to let the crack grow out of the major part of the plastic zone generated during pre-cracking. 
The experimental crack paths for all the tests are shown in Figs. 3-4. It is worth noting that, for simplifying the comparison between numerical and experimental results, both static and cyclic loading directions are reported in Figs. 3-4, i.e. the static load is applied from the lower left to the upper right of the figure, whereas the cyclic load is applied from the upper left to the lower right.

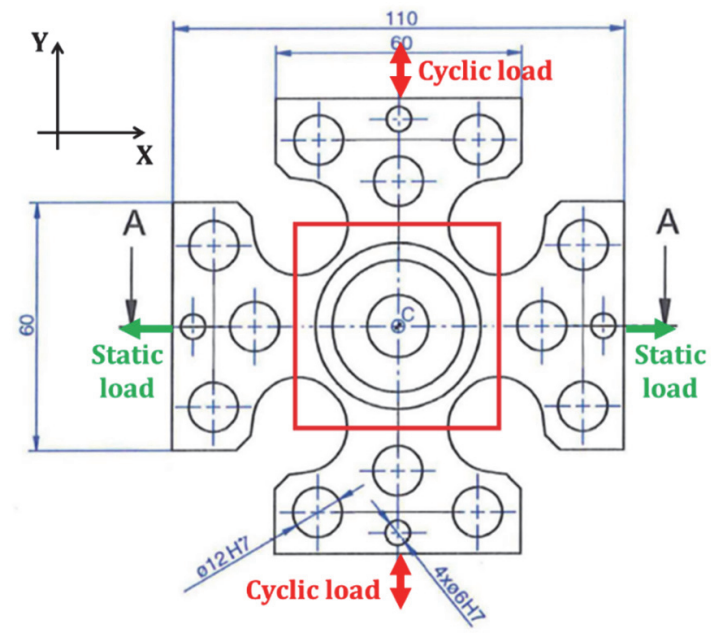

(a)

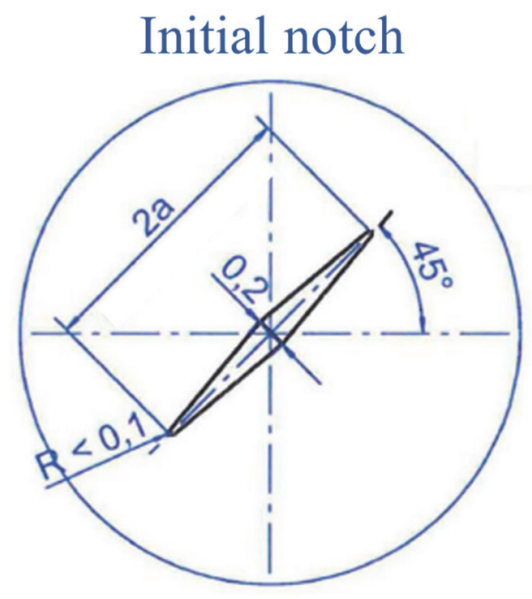

(b)

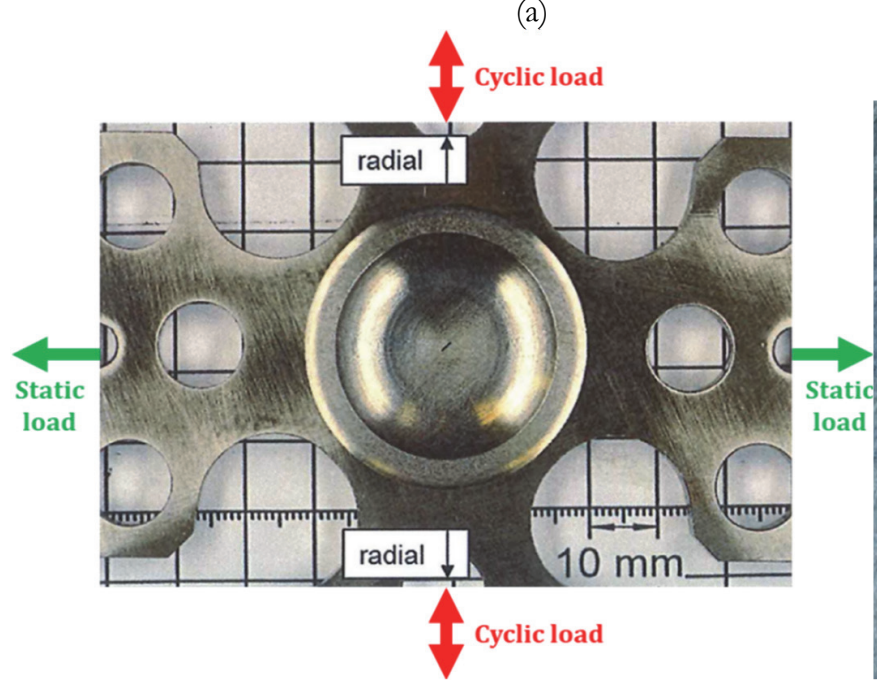

(c)

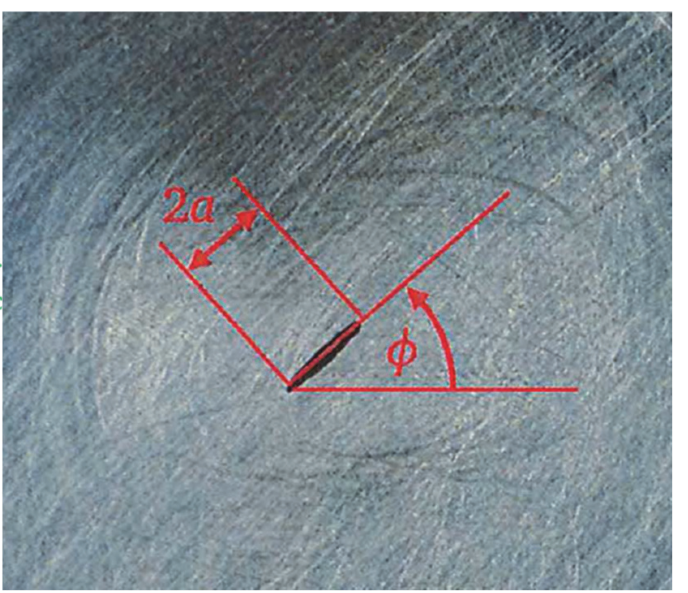

(d)

Figure 2: (a) Drawings of the cruciform specimen (red square defining the portion considered for the numerical analyses) with (b) closeup of the initial notch; (c) specimen photo with (d) close-up of the initial notch. (Courtesy of Christian Kontermann, TU Darmstadt, Germany)

\begin{tabular}{cccccc}
\hline \multirow{2}{*}{ Test [-] } & Load step [-] & Static load magnitude $[\mathrm{kN}]$ & Amplitude $[\mathrm{kN}]$ & $\begin{array}{c}\text { Load ratio } \\
\mathrm{R}[-]\end{array}$ & Frequency [Hz] \\
\hline I & 1 & 24.0 & 8.0 & -1 & 5 \\
\hline II & 1 & 3.0 & 24.0 & -1 & 5 \\
\hline
\end{tabular}

Table 1: Loading conditions for the tests.

\begin{tabular}{ccccc}
\hline $\mathrm{E}[\mathrm{GPa}]$ & $v[-]$ & $\mathrm{C}\left[\mathrm{mm} / \mathrm{cycle} /\left[\left(\mathrm{MPa} \mathrm{mm} \mathrm{m}^{\wedge} 0.5\right)^{\wedge} m\right]\right]$ & $m[-]$ & $w[-]$ \\
120.4 & 0.32 & $4.83828 \mathrm{E}-13$ & 3 & 0.67 \\
\hline
\end{tabular}

Table 2: Main mechanical properties and Walker law parameters of Ti6246. 
For Test I (Fig. 3), the crack propagation takes place in a direction orthogonal to the static load. On the contrary, the absence of a static loading would lead to a crack propagation direction orthogonal to the cyclic loading. This means that a transition of the crack propagation direction from orthogonal to the cyclic loading to orthogonal to the static loading must take place for a static load in between $0 \mathrm{kN}$ and $24 \mathrm{kN}$ (always considering a cyclic load of $\pm 8 \mathrm{kN}$ ). Test II (Fig. 4) was scheduled for better understanding such a transition behavior.

In order to investigate the range of low static loads, the static and cyclic load were initially set up in Test II (Fig. 4) to $3 \mathrm{kN}$ and $\pm 24 \mathrm{kN}$, respectively. The crack propagated mostly in the initial notch plane for this load step. Increasing the static load to $12 \mathrm{kN}$ in the next load step, crack directions did not change significantly its initial pattern (Fig. 4b).

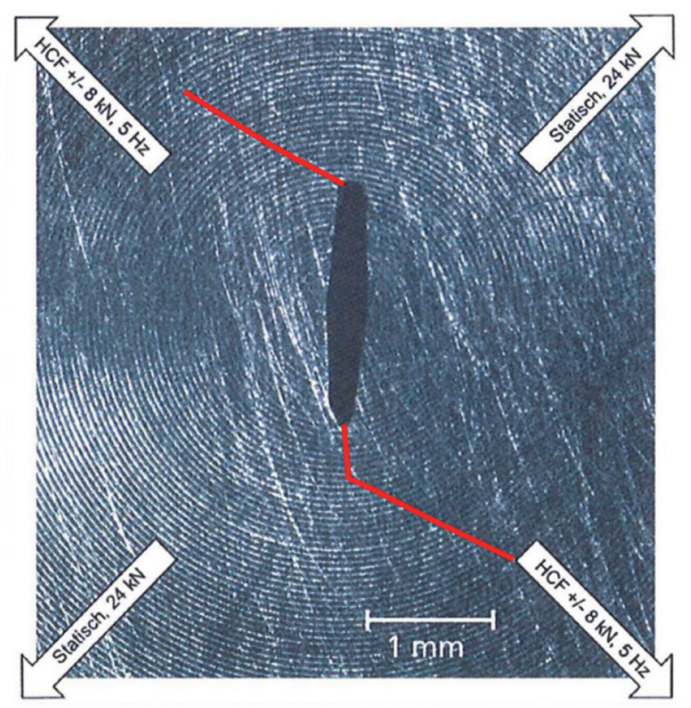

Figure 3: Experimental crack paths for Test I. (Courtesy of Christian Kontermann, TU Darmstadt, Germany)

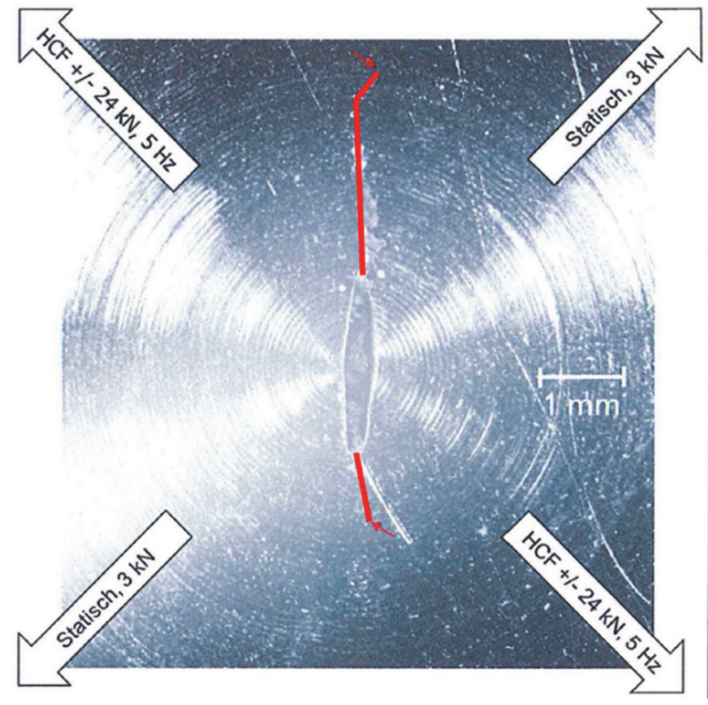

(a)

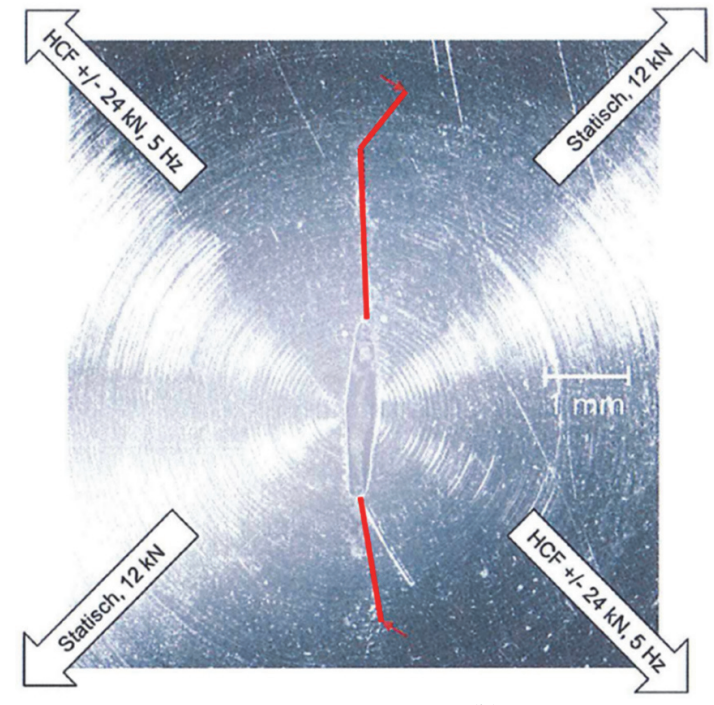

(b)

Figure 4: Experimental crack paths for Test II: (a) load step 1; (b) load step 2. (Courtesy of Christian Kontermann, TU Darmstadt, Germany)

\section{NUMERICAL CALCULATIONS}

$\mathrm{N}$ umerical simulations were performed with the BEASY DBEM code [19] and with the FRANC3D FEM code [2]. Cruciform specimens here considered have a non-uniform thickness and therefore the models presented in the followings are three-dimensional. 
Details of the procedures adopted numerically are illustrated in the followings.

\section{DBEM MODEL}

The portion of the cruciform specimen circumscribed by the dashed red line in Fig. $2 \mathrm{~b}$ was considered as initial model for the DBEM analyses (Fig. 5).

The initial notch with two cracks, initiated at $45^{\circ}$ at the two opposite tips after the pre-cracking phase, was considered as the initial configuration for the DBEM simulations (Fig. 5c). The total length of the notch and cracks was equal to 2 mm, consistent with the specimen experimentally tested.

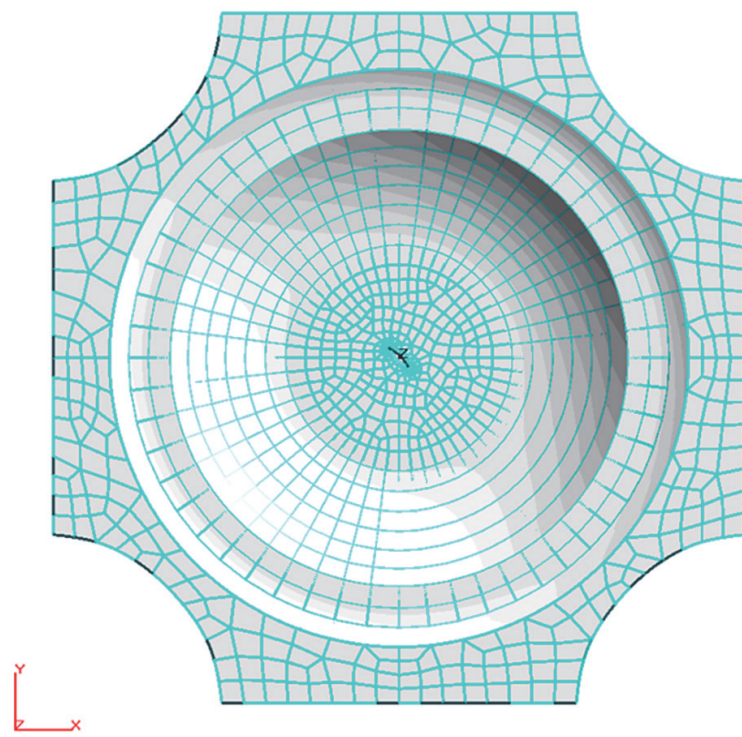

(a)

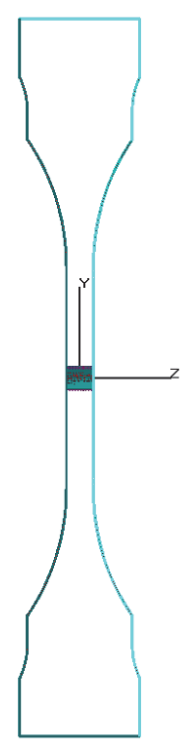

(b)

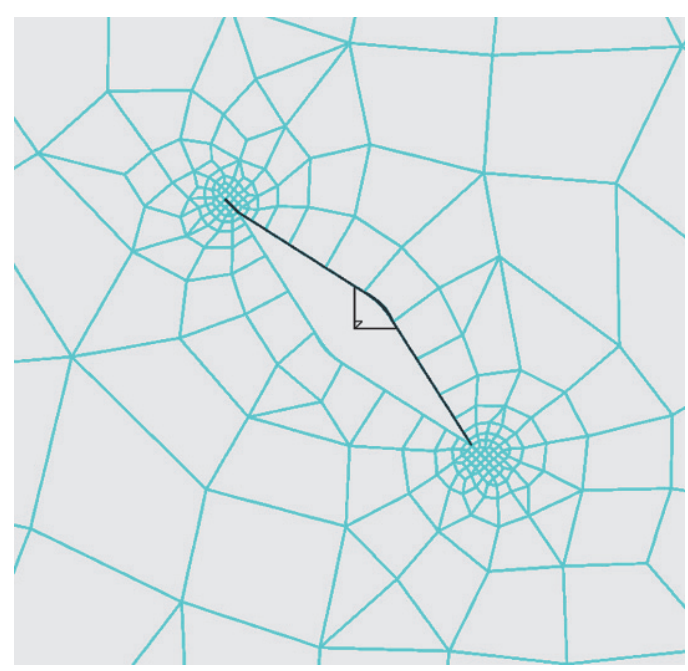

(c)

Figure 5: (a)-(b) DBEM model with (c) close-up of the initial cracked configuration

All the simulations considered a mission profile defined by means of two load cases built as in the following:

A. static tensile load in $\mathrm{X}$ direction plus cyclic tensile load in $\mathrm{Y}$ direction (load case $\mathrm{A}$ );

B. static tensile load in $\mathrm{X}$ direction plus cyclic compressive load in $\mathrm{Y}$ direction (load case B).

Rings of internal points (J-paths) were introduced along the two crack fronts in order to compute the corresponding Jintegral values. The $\mathrm{J}$ distributions were then used to compute $\mathrm{K}_{\mathrm{I}}, \mathrm{K}_{\mathrm{II}}$, and $\mathrm{K}_{\mathrm{III}}$ values along the crack front by means of the procedure developed in [20, 21]. The Yaoming-Mi formula (Eq. 1) [22] was used to combine the K values corresponding to the three basic modes into an equivalent $K_{\mathrm{eq}}$ parameter, to be used in the Walker crack-growth law (Eq. 2) [23], whose coefficients are listed in Tab. 1.

A crack-growth angle $\theta^{\mathrm{i}}$ was computed by means of the Minimum Strain Energy Density (MSED) [24, 25] criterion for each i-th load case (i.e. load cases "A" and "B"). MSED criterion considers as the growth angle, the one that minimize the strain energy density defined in terms of $\mathrm{K}$ (Eq. 4). Final kink angle was calculated by a weighted average of $\theta^{\mathrm{i}}$ by means of Eq. 5, whose weights are the $K_{\text {eq }}$ values for each load case.

For some combinations of static and cyclic load magnitudes, load case "B" provided negative $\mathrm{K}_{\mathrm{I}}$ values, with no physical meaning since representative of mutual intersection of crack faces. To circumvent this drawback, a nonlinear contact condition, with allowance for friction (friction coefficient $=0.3$ ), was applied to the crack face elements for such load cases. In this way, the resulting $K_{I}$ values became negligible and the related $K_{I I}$ and $K_{I I I}$ decreased due to friction effects, with a corresponding impact on the $\mathrm{K}_{\mathrm{eq}}$ values and eventually on the final growth angle $\theta$ (Eq. 5).

$$
\begin{aligned}
& K_{e q}=\sqrt{\left(K_{I}+\left|K_{I I I}\right|\right)^{2}+2 K_{I I}^{2}} \\
& \mathrm{da} / \mathrm{dN}=\mathrm{C}\left[\Delta \mathrm{K}_{e q} /(1-\mathrm{R})^{1-\mathrm{w}}\right]^{\mathrm{m}}
\end{aligned}
$$




$$
\begin{aligned}
& \mathrm{R}=\mathrm{K}_{e q, \text { min }} / \mathrm{K}_{e q, \text { max }} \\
& S(\theta)=a_{11}(\theta) K_{I}^{2}+a_{13}(\theta) K_{I} K_{I I}+a_{22}(\theta) K_{I I}^{2}+a_{33}(\theta) K_{I I I}^{2} \\
& \theta=\frac{\theta^{A}\left|K_{e q}^{A}\right|+\theta^{B}\left|K_{e q}^{B}\right|}{\left|K_{e q}^{A}\right|+\left|K_{e q}^{B}\right|}
\end{aligned}
$$

\section{FEM MODEL}

The portion of the cruciform specimen circumscribed by the dashed red line in Fig. $2 \mathrm{~b}$ was considered as initial model also for the FEM simulations (Fig. 6). No notch neither contacts between crack faces were considered and, as an alternative, a single crack with a total length of $2 \mathrm{~mm}$ was considered (Fig. 6c). The FEM simulations considered the same mission profile as for the DBEM analyses, thus cycling between load case A and load case B.

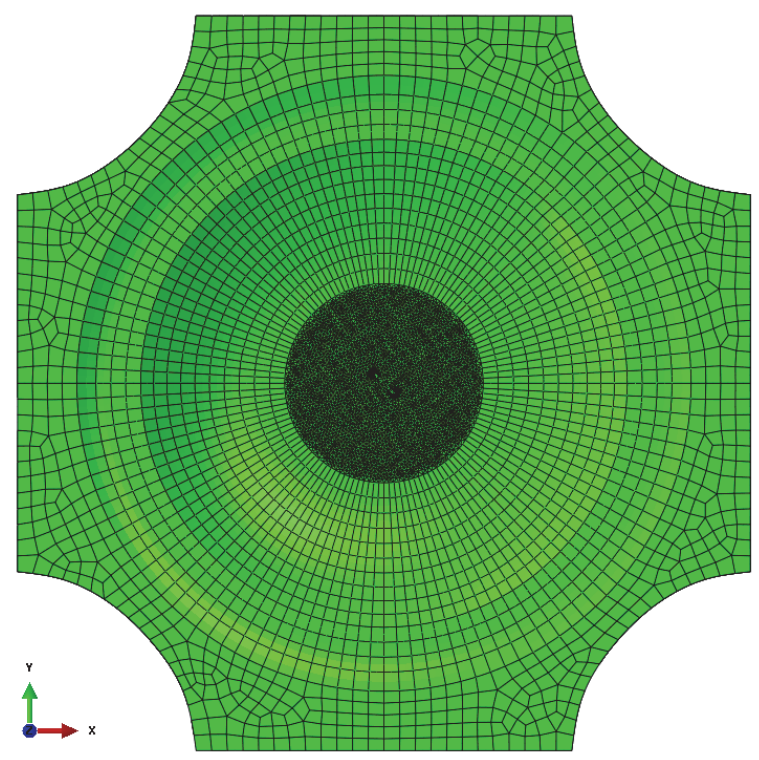

(a)

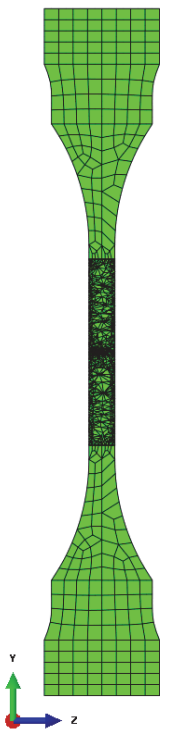

(b)

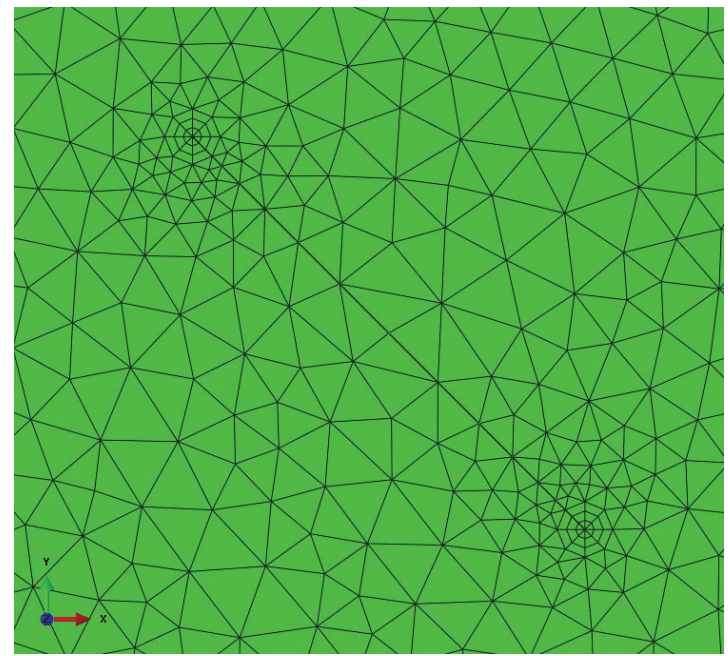

(c)

Figure 6: (a)-(b) FEM model with (c) close-up of the initial cracked configuration.

The M-integral formulation [26] was used to calculate the three single $\mathrm{K}$ values directly and, consequently, a $\mathrm{K}_{\mathrm{eq}}$ was derived with a sum of squares of the three $\mathrm{K}$ values (Eq. 6) to be used in the Walker crack-growth law (Eq. 2).

A crack-growth angle $\theta^{i}$ was computed by means of the Maximum Tensile Stress (MTS; Fig. 7) criterion for each load case, i.e. load cases A and B; MTS states that the crack kinks in the direction where tensile stress ahead of crack front points is maximized.

A crack-growth rate $\mathrm{da} / \mathrm{dN}_{\mathrm{i}}$ was computed for each load case with the Eq. 7, where $\mathrm{da} / \mathrm{dN}$ is the crack-growth rate computed for any given crack front point and $n$ is the number of load ranges in the spectrum. Finally, the corresponding predicted kink angle is a weighted average kink angle computed with Eq. 8, where $\theta^{\mathrm{i}}$ is the kink angle determined for load case $i$ using the MTS.

$$
\begin{aligned}
& K_{e q}=\sqrt{K_{I}^{2}+K_{I I}^{2}+K_{I I I}^{2}} \\
& \mathrm{da} / \mathrm{dN}=\frac{\sum_{i=1}^{n} \frac{d a}{d N_{i}}\left(\Delta K_{i}, R_{i}\right)}{n}
\end{aligned}
$$




$$
\theta=\frac{\sum_{i=1}^{n} \frac{d a}{d N_{i}}\left(\Delta K_{i}, R_{i}\right) \times \theta_{i}\left(K_{I, i}, K_{I I, i}, K_{I I I, i}, \ldots\right)}{\sum_{i=1}^{n} \frac{d a}{d N_{i}}\left(\Delta K_{i}, R_{i}\right)}
$$

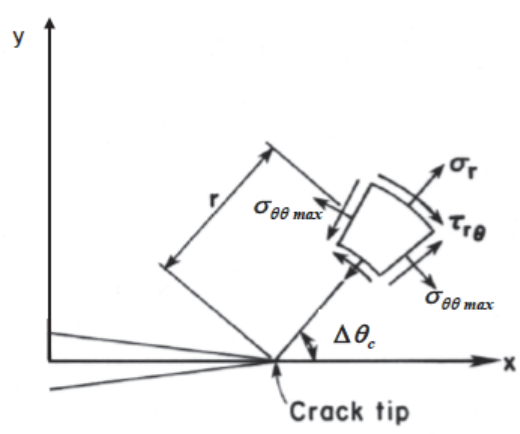

$$
\begin{gathered}
\sigma_{\theta \theta}=\frac{1}{\sqrt{2 \pi r}} \cos \frac{\theta}{2}\left[K_{I} \cos ^{2} \frac{\theta}{2}-\frac{3}{2} K_{I I} \sin \theta\right] \\
\Delta \theta_{c}=2 \tan ^{-1}\left(\frac{1-\sqrt{1+8\left(K_{I I} / K_{I}\right)^{2}}}{4\left(K_{I I} / K_{I}\right)}\right)
\end{gathered}
$$

Figure 7: MTS kink angle theory used for the FEM analyses.

\section{RESULTS}

$\mathrm{D}$

BEM and FEM analyses were performed to simulate the loading conditions of Test I. For Test I, the static load was set to $24 \mathrm{kN}$ and the cyclic load was set to $\pm 8 \mathrm{kN}$ (Tab. 1). Experimental and numerical crack propagation paths are compared in Fig. 8. For such numerical analysis, neither initial notch shape (approximated by a sharp crack) nor contacts on the crack faces were considered; such simplifications allowed to decrease the runtimes with a negligible impact on the results since the combination of static and cyclic loads led to completely open crack faces during the entire fatigue cycle. The agreement between crack-growth directions and crack-growth rates was very sound among FEM, DBEM and experimental results. In summary, for this case it is possible to assess that:

- the calculation of the equivalent $\mathrm{K}$-factor in combination with a classical crack propagation law calibrated by ModeI test data yields a correct crack propagation prediction;

- the procedures for the calculation of the propagation angle seems to be correct.

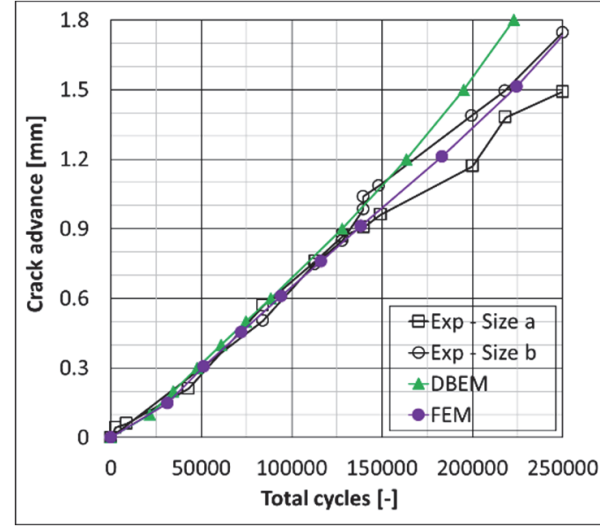

(a)

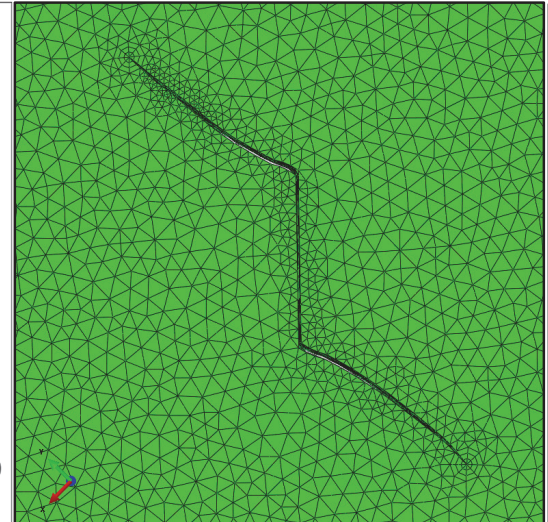

(b)

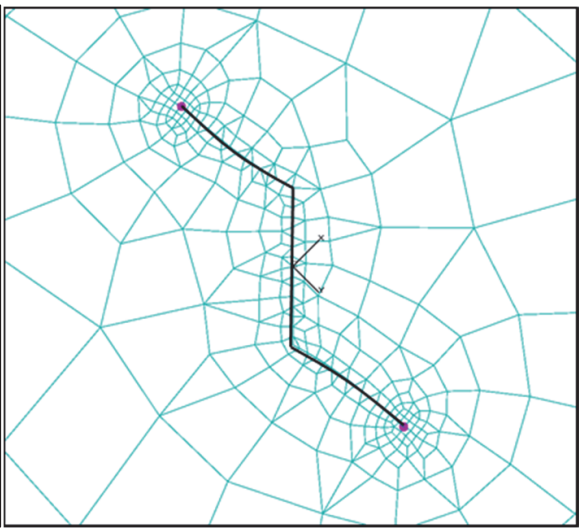

(c)

Figure 8: Results for Test I: (a) crack-growth rates; (b) FEM and (c) DBEM crack-growth directions; experimental crack-growth direction shown in Fig. 3.

Test II was simulated with the DBEM code. No FEM analyses were performed with FRANC3D for this test since the MTS and Max Shear Stress (MSS) criteria implemented in the code were not able to satisfactorily capture the crack-growth direction. The code implements also more advanced crack-growth criteria but no dedicated material data were available for their calibration. 
The corresponding load levels are those listed in Tab. 1 and, in particular, load step 1 (static load $=3 \mathrm{kN}$; cyclic load $= \pm 24$ $\mathrm{kN}$ ) was applied for 15.000 fatigue cycles whilst load step 2 (static load $=12 \mathrm{kN}$; cyclic load $= \pm 24 \mathrm{kN}$ ) was applied for 5.000 more fatigue cycles. Results for this test are shown in Fig. 9 showing a satisfactory agreement.

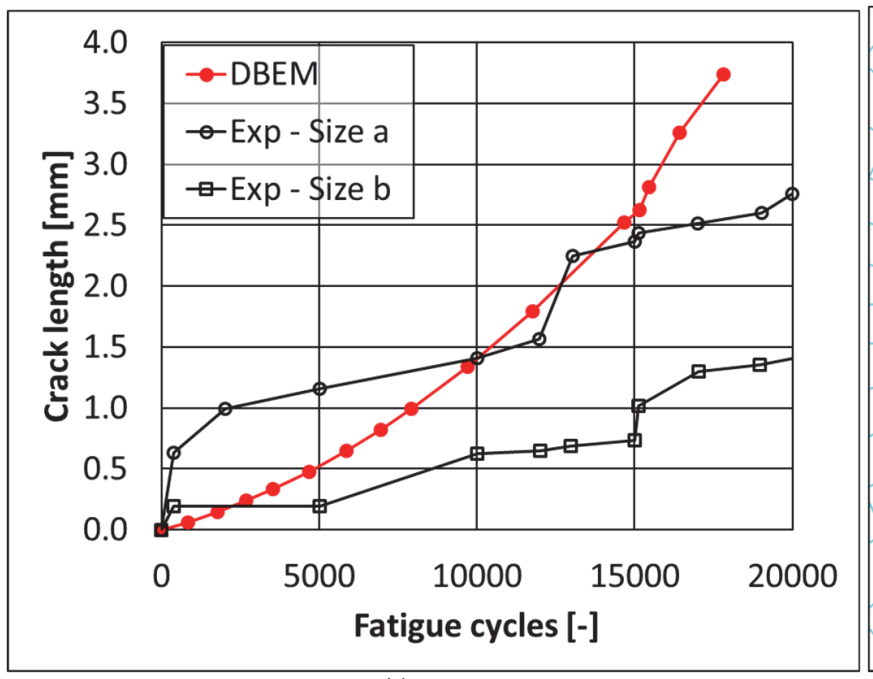

(a)

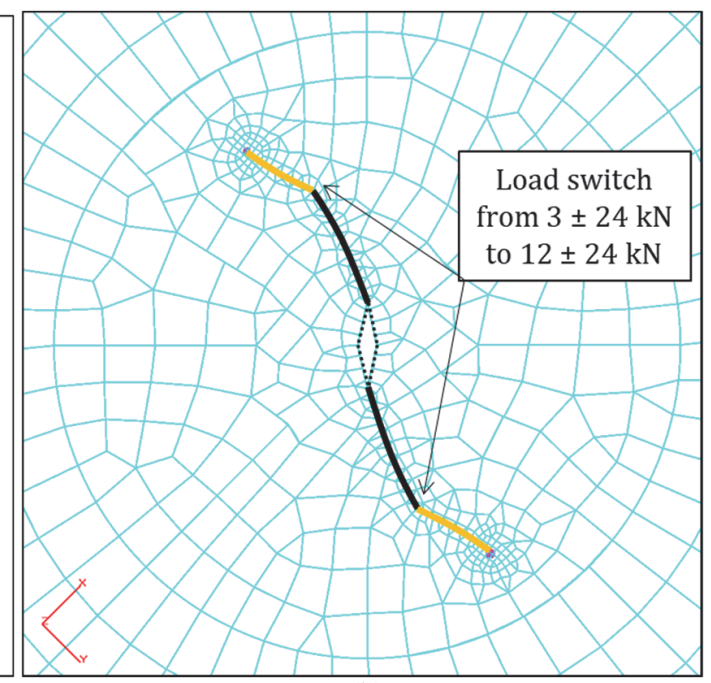

(b)

Figure 9: Results for Test II: (a) crack-growth rates; (b) DBEM crack-growth directions; experimental crack-growth direction shown in Fig. 4b.

\section{CONCLUSIONS}

$\mathrm{C}$

ruciform specimens subject to static loading in one direction and cyclic loading in the other orthogonal direction were simulated by a DBEM and a FEM code.

loads.

Experimental tests were performed on cruciform specimens undergoing various combinations of static and cyclic

Regarding the DBEM, a peculiar procedure for crack propagation angle assessment was pointed out and the allowance for friction between crack faces was provided when required.

The agreement among experimental and numerical results in terms of crack-growth rates and crack paths seems to be very good.

\section{REFERENCES}

[1] Newman, Jr., J.C. and Raju, I.S. (1979). Analysis of surface cracks in finite plates under tension or bending loads, NASA TP-1578.

[2] Wawrzynek, P.A., Carter, B.J. and Ingraffea, A.R. (2009). Advances in simulation of arbitrary 3d crack growth using FRANC3D/NG, in: Proceedings of the 12th international conference on fracture, Ottawa, Canada.

[3] Bremberg, D. and Dhondt, G. (2009). Automatic 3-D crack propagation calculations: a pure hexahedral element approach versus a combined element approach, Int J Fract., 157, pp. 109-118. DOI: 10.1007/s10704-009-9313-z.

[4] Citarella, R., Lepore, M., Maligno, A. and Shlyannikov, V. (2015a). FEM simulation of a crack propagation in a round bar under combined tension and torsion fatigue loading, Frattura ed Integrità Strutturale, 31, pp. 138-147.

DOI: 10.3221/IGF-ESIS.31.11.

[5] Citarella, R., Giannella, V., Lepore, M. and Dhondt, G. (2018). Dual boundary element method and finite element method for mixed-mode crack propagation simulations in a cracked hollow shaft, Fatigue Fract Eng Mater Struct. 41, pp. 84-98. DOI: $10.1111 /$ ffe.12655.

[6] Citarella, R. and Cricrì, G. (2014). Three-dimensional BEM and FEM submodelling in a cracked FML full scale aeronautic panel, Appl. Compos. Mater., 21(3), pp. 557-577. DOI: 10.1007/s10443-014-9384-5. 
[7] Citarella, R., Lepore, M., Fellinger, J., Bykov, V. and Schauer, F. (2013). Coupled FEM-DBEM method to assess crack growth in magnet system of Wendelstein 7-X, Fract. Struct. Integ., 26, pp. 92-103. DOI: 10.3221/IGF-ESIS.26.10.

[8] Citarella, R., Cricrì, G., Lepore, M. and Perrella, M. (2014). Assessment of crack growth from a cold worked hole by coupled FEM-DBEM approach, Key Engineering Materials. vols. 577-578, Trans Tech Publications, Switzerland, pp. 669-672. DOI: 10.4028/www.scientific.net/KEM.577-578.669.

[9] Carlone, P., Citarella, R., Lepore, M. and Palazzo, G.S. (2015). A FEM-DBEM investigation of the influence of process parameters on crack growth in aluminium friction stir welded butt joints, Int. J. Mater. Form., 8(4), pp. 591-599. DOI: $10.1007 /$ s12289-014-1186-7.

[10] Citarella, R., Carlone, P., Lepore, M. and Palazzo, G.S. (2015b). Numerical-experimental crack growth analysis in AA2024-T3 FSWed butt joints, Adv. Eng. Softw., 80, pp. 47-57. DOI: 10.1016/j.advengsoft.2014.09.018.

[11] Citarella, R., Carlone, P., Sepe, R. and Lepore, M. (2016a). DBEM crack propagation in friction stir welded aluminum joints, Adv. Eng. Softw., 101, pp. 50-59. DOI: 10.1016/j.advengsoft.2015.12.002.

[12] Citarella, R., Carlone, P., Lepore, M. and Sepe, R. (2016b). Hybrid technique to assess the fatigue performance of multiple cracked FSW joints, Eng. Fract. Mech., 162, pp. 38-50. DOI: 10.1016/j.engfracmech.2016.05.005.

[13] Citarella, R. and Cricrì, G. (2009). A two-parameter model for crack growth simulation by combined FEM-DBEM approach, Adv. Eng. Softw., 40(5), pp. 363-377. DOI: 10.1016/j.advengsoft.2008.05.001.

[14] Citarella, R., Giannella, V., Vivo, E. and Mazzeo, M. (2016c). FEM-DBEM approach for crack propagation in a low pressure aeroengine turbine vane segment, Theoretical and Applied Fracture Mechanics., 86(B), pp. 143-152. DOI: $10.1016 /$ j.tafmec.2016.05.004.

[15] Giannella, V., Fellinger, J., Perrella, M. and Citarella, R. (2017a). Fatigue life assessment in lateral support element of a magnet for nuclear fusion experiment "Wendelstein 7-X", Engineering Fracture Mechanics, 178, pp. $243-257$. DOI: $10.1016 /$ j.engfracmech.2017.04.033.

[16] Giannella, V., Perrella, M. and Citarella, R. (2017b). Efficient FEM-DBEM coupled approach for crack propagation simulations, Theoretical and Applied Fracture Mechanics, 91, pp. 76-85. DOI: 10.1016/j.tafmec.2017.04.003.

[17] Erdogan, F. and Sih, G.C. (1963). On the extension of plates under plane loading and transverse shear, J Basic Eng., 85D(4), pp. 519-27. DOI: 10.1115/1.3656897.

[18] Dhondt, G. and Kontermann, C. (2018). Combined LCF-HCF Multi-Axial Crack Propagation in Cruciform Specimens, CP2018, Verona, Italy.

[19] Computational Mechanics, BEASY, Ver. 10.0r18, (2017).

[20] Rigby, R.H., Aliabadi, M.H. 1993. Mixed-mode J-integral method for analysis of 3D fracture problems using BEM. Eng. Anal. Boundary Elem. 11, 239-256. DOI: 10.1016/0955-7997(93)90026-H.

[21] Rigby, R.H. and Aliabadi, M.H. (1998). Decomposition of the mixed-mode J-integral - revisited, Int. J. Solids Struct., 35(17), pp. 2073-2099. DOI: 10.1016/S0020-7683(97)00171-6.

[22] Mi, Y. (1995). Three dimensional dual boundary element analysis of crack growth, PhD Thesis, Portsmouth.

[23] Walker, K. (1970). The Effect of Stress Ratio During Crack Propagation and Fatigue for 2024-T3 and 7075-T6 Aluminum, American Society for Testing and Materials, ASTM STP 462. DOI: 10.1520/STP32032S.

[24] Sih, G.C. (1974). Strain energy density factor applied to mixed mode crack problems, Int J Fract., 10, pp. 305-321. DOI: $10.1007 /$ BF00035493.

[25] Sih, G.C., Cha, B.C.K. (1974). A fracture criterion for three-dimensional crack problems, Eng Fract Mech, 6(4), pp. 699-723. DOI: 10.1016/0013-7944(74)90068-X.

[26] Wawrzynek, P.A., Carter, B., and Banks-Sills, L. (2005). The M-integral for computing stress intensity factors in generally anisotropic materials, NASA/CR-2005-214006. 